\title{
Turnover Premium, Foreign Institutional Ownership, and Time- Varying Risk Premium in Taiwan Equity Markets
}

\author{
Ying-Jen Chen ${ }^{*}$ and Jen-Sin Lee
}

\author{
Finance Department, I-Shou University, Taiwan
}

\begin{abstract}
The low turnover premium found in U.S. equity markets is also found in Taiwan market, unlike the mixed evidence for other stylized effects such as size, book-to-market ratio and momentum. Consistent with investor overconfidence hypothesis proposed by Odean $(1998,1999)$, the percentage of foreign institutional shareholdings in a stock is found to vary inversely with turnover premium. This inverse relation is robust to the influence of other forces that may interact with turnover rate, such as market capitalization, book-to-market ratio and 6-month past returns, respectively. Time-varying risk premium, particularly in low turnover-low foreign institutional shareholdings percentage portfolio, provides partial explanation for the phenomenon, but the inverse relation persists after risk adjustment by models such as unconditional CAPM, Fama-French three factor model and conditional CAPM.
\end{abstract}

Keywords: Turnover Premium, Foreign Institutional Investors, Time-Varying Risk Premium, Overconfidence.

\section{INTRODUCTION}

The role of trading volume in asset pricing has drawn attention from financial economists during at least the past two decades. Trading volume is often measured by dividing the trading volume of a stock to its number of shares outstanding, or the so-called turnover ratio. Most researchers reported a positive and significant turnover premium defined as the average return to a strategy that is simultaneously long on low- and short on high-turnover stocks, in stock returns (Datar et al. 1998; Chou et al. 2013). The sources of the turnover premium, however, remain elusive.

Investor overconfidence has been advanced as a plausible explanation for excessive trading volumes. Odean (1998) investigated how overconfidence may influence security price changes and trading volumes under three market settings, namely, price-takers, insiders and market makers with costly information, that principally differ in how information is distributed. In all three market settings, the presence of overconfident trader increases expected trading volume, a result that provides the theoretical linkage between overconfidence and trading volume.

Using account data obtained from a discount broker, Barber and Odean (2000) documented excessive trading by individual investors that eventually led to annual returns below the market. Gervais and Odean (2001) predicted that investors who have experienced high past returns will be more prone to

*Address correspondence to this author at the No.276, Lane 8, Sec. 1, Syuecheng Rd., Dashu District, Kaohsiung City 84001, R.O.C., Taiwan; Tel: +01188676567189; E-mail: yingjenchen@yahoo.com JEL Classification: G12. overconfidence than otherwise, a prediction that was supported by the empirical evidence provided by Statman et al. (2006). The latter study further reported that trading volume, as measured by turnover ratios, was more responsive to market-wide return shocks than to security return shocks, especially for small-cap stocks.

Some researchers investigated the patterns of trading behavior between institutional and individual investors, and how the diverging patterns between these two types of investors may be related to the low turnover premium phenomenon. For example, Odean (1999) argued that, when making stock purchase decisions, investors tend to limit their search to attention-grabbing stocks due to limitation of resource. The problem is more severe for individual than institutional investors, as the latter are endowed with more resource to conduct equity research than the former. Barber and Odean (2008) tested this proposition empirically by examining the trading records of individual accounts at discount brokers and those of professional money managers respectively. They found that individual investors tended to be the net buyer of a stock that had recently experienced high abnormal trading volume or extreme one-day return, while the investing decision of institutional investors was not sensitive to these attention-grabbing events. Using a complete trading history of both institutional investors and individual investors obtained from Taiwan Stock Exchange between 1995 and 1999, Barber et al. (2009) documented that, as a group, individual investors lost money, especially on aggressive trades, to institutional investors. Notably, about half of the trading loss by individual investors was earned by foreign institutional investors. The authors reported 
annual turnover of $300 \%$ annually during this period, which implies that excessive trading led to institutional gains at the expense of individual investors. Chordia et al. (2011) examined the trends in trading activity in financial markets. They noted that the average monthly turnover on the NYSE had increased from about $5 \%$ in 1993 to about $26 \%$ toward the end of 2008 . The primary source of the surging turnover may be attributed to the increased institutional trading, and the increased trades tended to be information-based.

Chuang and Susmel (2011) compared the trading behavior of both institutional and individual investors in Taiwan, as some psychological evidence, such as Yates et al. (1996, 1997, 1998), suggested that Asians may be overconfident in general knowledge as well as in making probabilistic assessment. Although both institutional and individual investors were found to trade more aggressively following market gains, the latter were more prone to trade in riskier securities than the former. The evidence therefore supported the notion that individual investors are more overconfident than their institutional counterpart. Using intra-day high frequency data obtained from Taiwan Stock Exchange, Hsieh (2013) reported that institutional trades tended to reflect private information, while individual trades tended to be driven by emotion and behavioral reasons.

The research cited above implies the following testable hypothesis: The relation between the trading volume and future return of a stock may be affected by the extent to which institutional investors is involved. When a stock is purchased by a high percentage of institutional investors relative to individual investors, a higher turnover rate will not necessarily results in lower future return than stocks with low turnover rate because institutional investors tend to trade on private information. In contrast, a high turnover stock with low institutional participation could mean that individual investors are herding to buy riskier stock due to overconfidence. As Odean (1998) pointed out, when price-takers such as individual investors are overconfident, their trades tend to push prices further away from true value. The eventual price reverse of high turnover stocks would then cause low future return relative to low turnover stocks. Consequently, one would expect low turnover premium to be more pronounced in stocks with low institutional participation than those with high institutional interest. In particular, this study will examine the role of foreign institutional investors in the relation between turnover rate and expected return. Extant research suggested that the presence of foreign institutional investors in emerging markets tended to improve market efficiency (Yang 2002; Schuppli and Bohl 2010; He and Shen 2014; Shiu et al. 2014), which could help tame the turnover premium when overconfidence was pungent.

Previous research typically employed Capital Asset Pricing Model (CAPM) or Fama-French three-factor model (FF) to risk adjust returns. The implicit assumption is that equity risk premium is constant through time. Since these unconditional risk adjustments failed to capture low turnover premium, researchers logically attributed this phenomenon to behavioral bias such as investor overconfidence. However, various researches have suggested that equity risk premium may be time-varying (Ferson 1989; Ferson and Harvey 1991; Ferson and Harvey 1999; Lettau and Ludvigson 2001; Kang et al. 2011). In light of these findings, this paper will use the conditional CAPM framework proposed by Lettau and Ludvigson (2001) and Kang et al. (2011), alongside the CAPM and $F F$, for risk adjustment purpose. The specifics of the conditional CAPM employed in this paper will be discussed in detail in due course.

The research methodology employed for this paper will be discussed in section II. Empirical findings will be discussed in section III, while the conclusion will be presented in section IV.

\section{DATA AND METHODOLOGY}

The data used in this paper is obtained from Taiwan Economic Journal (TEJ) database. The time series of monthly return, turnover rate, foreign institutional investing percentage (FINI percentage henceforth), market capitalization and book-to-market ratio for all stocks listed on Taiwan Stock Exchange (TSE) and OTC market (GreTai), excluding TDR and foreign companies, are collected from January 1994 through June 2014. The series for Taiwan leading and coincident indicators are also collected.

\section{A. Construction of Turnover Portfolios}

The test portfolios for this paper are created by the following process. Initially, all stocks that are included in a given month are ranked on the basis of turnover rate. Stocks with turnover rate below the $30^{\text {th }}$ percentile are placed into the Low TO group, while those above the $70^{\text {th }}$ percentile in the High TO group, with the rest placed into the Medium TO camp. The returns of stocks in the following month in each portfolio are than 
value-weighted to arrive at the portfolio return for that month. These portfolio returns are updated monthly. In the second stage, a double-sort procedure is employed to examine potential interaction of each of the following variables with turnover premium: market capitalization, book-to-market ratio, past return and FINI percentage. Finally, a triple-sort procedure will be used to disentangle the joint influence of the following variables with FINI percentage on turnover premium: market capitalization, book-to-market ratio, and past return.

After all required test portfolio are created, their returns must be adjusted for risk. The conventional CAPM and FF 3-factor models will be employed for this purpose. However, in light of the aforementioned timevarying risk premium literature, a conditional CAPM will be used alongside with the conventional riskadjustment models, which will be discussed in detail in the next subsection.

\section{B. Construction of Conditional CAPM and Conditioning Information}

Lettau and Ludvigson (2001, LL2001 henceforth) proposed a framework to construct a conditional CAPM that provided reasonable description for the crosssectional variation of expected returns. One key piece in their framework is the conditioning variable, the logconsumption to log-aggregate asset and income ratio, or simply "cay". The variable may be computed from the cointegrating vector in a Vector Error Correction Model (VECM) consisting of the three logged variables. However, these variables are available only at quarterly frequency, which renders them less useful when applied to countries with short historical data.

Kang et al. (2011, KKLM 2011 henceforth) proposed to use business condition variables that have been found to predict future equity market return as the conditioning variables, namely, short-term T-Bill rate, term premium, default premium and aggregate dividend yield. These variables are available monthly. The deviation from the cointegrating vector consisting of the four variables were found to have significant explanatory power over the cross-sectional variation in expected returns, including the momentum effect that has troubled the FF 3-factor model.

The conditioning variable proposed by KKLM 2011 relies on the availability of a well-developed fixedincome market with sufficient history that supplies market information crucial to compute two key variables, namely, term premium and default premium through time. However, such conditions are rarely satisfactorily met outside the U.S. market, especially among emerging market countries such as Taiwan. To apply the conditional CAPM framework employed by LL2001 and KKLM2011, one must find conditioning variables that are capable of reflecting business conditions with sufficient length of historical time series. Therefore, this paper proposes to employ two variables that have been constructed by most countries to provide guidance on the future and current states of their respective economies, namely, the composite leading indicator and the composite coincident indicator. In the section that follows, some evidence of return predictability of the deviation from the cointegrating vector between the two series will be presented before the model is used to adjust risk. The resulting conditional CAPM is specified as follows.

$r_{t}=\beta_{0}+\beta_{1} \cdot E C_{t-1}+\beta_{2} \cdot r_{M, t}+\beta_{3} \cdot E C_{t-1} \cdot r_{M, t}+\varepsilon_{t}$

where $r_{t}$ denotes the excess return of portfolio $i$ in month $t$, or the return on the hedge portfolio formed by buying low turnover and selling high turnover stocks, while $r_{M, t}$ denotes the value-weighted excess return of all stocks traded on Taiwan Stock Exchange and GreTai OTC market. The risk-free rate used in this paper is the average 1-month certificate deposit rate provided by the five major banks in Taiwan. This model, along with the following unconditional CAPM and FF 3-factor models, will be used for risk adjustment.

$r_{t}=\beta_{0}+\beta_{1} \cdot r_{M, t}+\varepsilon_{t}$
$r_{t}=\beta_{0}+\beta_{1} \cdot r_{M, t}+\beta_{2} \cdot S M B_{t}+\beta_{3} \cdot H M L_{t}+\varepsilon_{t}$

The term $E C_{t-1}$ from equation (1) denotes the error correction term formed by the cointegrating relation between logged leading and coincident indicators, which is part of the Vector Error Correction Model (VECM) specified below:

$$
\begin{aligned}
& \Delta \ln (L)_{t}=\gamma_{10}+\gamma_{11} \cdot E C_{t-l}+\sum_{j=1}^{12} \alpha_{l j} \cdot \Delta \ln (L)_{t-j} \\
& +\sum_{j=1}^{12} \delta_{l j} \cdot \Delta \ln (C)_{t-j}+\varepsilon_{l t} \\
& \Delta \ln (C)_{t}=\gamma_{20}+\gamma_{2 l} \cdot E C_{t-1}+\sum_{j=l}^{12} \alpha_{2 j} \cdot \Delta \ln (L)_{t-j} \\
& +\sum_{j=1}^{12} \delta_{2 j} \cdot \Delta \ln (C)_{t-j}+\varepsilon_{2 t}
\end{aligned}
$$




$$
E C_{t}=\phi_{1} \cdot \ln (L)_{t}+\phi_{2} \cdot \ln (C)_{t}
$$

The term $\ln (L)_{t}$ and $\ln (C)_{t}$ denote, respectively, the natural logarithm of composite leading and coincident indicators. Following the framework in LL2001 and JJLM2011, the following tests are performed to determine the existence of cointegrating relation between the business indicators. Panel $A$ of Table 1 presents Augmented Dickey-Fuller and EngleGranger cointegration test results for the economic indicators, while panel B presents Johansen cointegration tests to further discern the existence of cointegration relation between the indicators. The estimates of coefficients for the error correction term from equation (5) are presented in panel $\mathrm{C}$. Based on the coefficient estimates presented in panel $C$, the conditioning variable, $E C_{t}$, will be constructed as follows:
$E C_{t}=\ln (L)_{t}-0.98975 \cdot \ln (C)_{t}$

If the $E C_{t-1}$ term so constructed is to be used as the conditioning variable in a conditional CAPM framework, it must exhibit some predictability of future market returns. Table 2 presents the forecasting regressions for various horizons, ranging from 1 month to 12 months ahead. The results indicate that the $E C$ term constructed in this paper predicted future market returns of up to 3 months, which qualifies it as a conditioning variable.

\section{EMPIRICAL FINDINGS}

The descriptive statistics of initial sorts are reported in Table 3. The statistics for portfolios sorted by the top and bottom $30 \%$ are reported in panel $A$, while those for the quintile sort in panel $B$. In panel $A$, the average return for the low turnover portfolio was $1.14 \%$ per

Table 1: Unit Root and Cointegration Test Results

\begin{tabular}{|c|c|c|}
\hline \multirow[t]{2}{*}{ Panel A. } & \multicolumn{2}{|c|}{ Unit Root Test } \\
\hline & ADF t-statistic & P-value \\
\hline $\ln (L)$ & -1.398 & {$[0.5850]$} \\
\hline \multirow[t]{2}{*}{$\ln (C)$} & -1.6751 & {$[0.4440]$} \\
\hline & \multicolumn{2}{|c|}{ Engle-Granger Cointegration Test } \\
\hline Residuals & -5.8957 & {$[0.0000]$} \\
\hline Panel B. & \multicolumn{2}{|c|}{ Johansen Cointegration Test } \\
\hline Rank & 0 & 1 \\
\hline Trace test & 34.245 & 2.1317 \\
\hline$P$ value & {$[0.0000]$} & {$[0.1454]$} \\
\hline Lmax test & 32.113 & 2.1317 \\
\hline P-value & {$[0.0000]$} & {$[0.1443]$} \\
\hline \multirow[t]{2}{*}{ Panel C. } & \multicolumn{2}{|c|}{ Cointegrating Equation } \\
\hline & Coefficient & P-value \\
\hline$\phi_{1}$ & 1 & \\
\hline$\phi_{2}$ & -0.98975 & [0.0054] \\
\hline
\end{tabular}

Table 2: Prediction Capability of Conditioning Variable, $E C_{t-1}$

\begin{tabular}{|c|c|c|c|c|}
\hline & 1 Month & 3 Month & 6 Month & 12 Month \\
\hline \hline Intercept & -0.0152 & -0.026 & -0.0032 & 0.0767 \\
\hline $\boldsymbol{t}$-statistic & {$\left[-1.84^{\star}\right]$} & {$[-1.08]$} & {$[-0.07]$} & 1.192 \\
\hline EC Term & 0.5529 & 1.1857 & {$[1.28]$} & 0.3746 \\
\hline $\boldsymbol{t}$-statistic & {$\left[3.64^{* * *}\right]$} & {$\left[2.57^{\star *}\right]$} & 0.0162 & {$[0.30]$} \\
\hline Adjusted $\mathbf{R}^{2}$ & 0.0396 & 0.0396 & -0.0017 \\
\hline
\end{tabular}


Table 3: Descriptive Statistics of Turnover Rate-Sorted Portfolios

\begin{tabular}{|c|c|c|c|c|c|c|c|}
\hline & \multicolumn{7}{|c|}{ Panel A. Turnover Portfolios Formed by Top-Bottom $\mathbf{3 0} \%$} \\
\hline & Mean & t-statistic & No. Sample & Maximum & Minimum & Skewness & Kurtosis \\
\hline Low & 0.0114 & {$\left[2.59^{* *}\right]$} & 245 & 0.2995 & -0.1919 & 0.5523 & 1.19 \\
\hline Medium & 0.0108 & {$\left[1.93^{*}\right]$} & 245 & 0.3686 & -0.2446 & 0.5320 & 1.47 \\
\hline High & 0.0031 & [0.49] & 245 & 0.4064 & -0.2970 & 0.2842 & 1.01 \\
\hline \multirow[t]{2}{*}{$L-H$} & 0.0083 & {$\left[2.31^{\star \star}\right]$} & 245 & 0.1637 & -0.2500 & -0.7017 & 2.41 \\
\hline & \multicolumn{7}{|c|}{ Panel B. Portfolios Formed by Quintile Sort } \\
\hline Low & 0.0116 & {$\left[2.72^{\star \star \star}\right]$} & 245 & 0.2927 & -0.1833 & 0.5909 & 1.22 \\
\hline 2 & 0.0116 & {$\left[2.27^{\star \star}\right]$} & 245 & 0.3225 & -0.2196 & 0.5597 & 1.17 \\
\hline 3 & 0.0107 & {$\left[1.88^{\star}\right]$} & 245 & 0.3711 & -0.2447 & 0.5284 & 1.52 \\
\hline 4 & 0.0083 & [1.38] & 245 & 0.3661 & -0.2674 & 0.3966 & 1.10 \\
\hline High & 0.0013 & {$[0.20]$} & 245 & 0.4300 & -0.3076 & 0.2980 & 1.20 \\
\hline$L-H$ & 0.0103 & {$\left[2.38^{\star \star}\right]$} & 245 & 0.2019 & -0.2969 & -0.6216 & 2.20 \\
\hline
\end{tabular}

month, which is significant at less than $1 \%$ level. The average return for the portfolio comprising the middle $40 \%$ stocks was $1.08 \%$ per month, but only significant at less than $10 \%$ level. In contrast, the average return for the top 30\% turnover stock was insignificantly different from zero at $0.31 \%$ per month. Consequently, the average turnover premium was $0.83 \%$ per month, which is significant at less than $1 \%$ level. A similar but stronger pattern is observed when stocks are sorted into turnover quintiles as shown in panel B. The average return for stocks with the lowest turnover rate was $1.16 \%$ per month, while that for the highest turnover stocks was $0.13 \%$ per month. This produces a monthly turnover premium of $1.03 \%$ that is significant at less than $1 \%$ level. Therefore, the statistics reported in Table 3 clearly established the existence of low turnover effect in Taiwan equities. This is quite different from other stylized market anomalies that were documented for most developed markets, but have been absent in Taiwan equity market, for example, book-to-market effect, momentum effect, size effect, etc.

\section{A. Turnover Rate Double-Sort Portfolios}

The influence of foreign institutional investors, or FINI, will be examined next. To discern the extent to which turnover effect is affected by the presence of FINI, a double-sort procedure is applied to produce 9 portfolios. Panel A of Table 4 below reports the descriptive statistics of the portfolios along with their respective average turnover rates and FINI investing percentages in a public company.

The 5th column in Table 4 shows the turnover premium associated with three levels of FINI\%, which is monotonically decreasing from $1.24 \%$ per month for low FINI\%, to $0.08 \%$ per month for high FINI\%. The average $\mathrm{FINI} \%$ for the three low FINI portfolios range from $0.25 \%$ to $0.32 \%$, while those for the three medium FINI\% portfolios range from $5.63 \%$ to $6.12 \%$. In contrast, the average FINI\% for the three high FINI portfolios are much higher, ranging from $33.08 \%$ to $29.52 \%$. The initial evidence therefore supports the notion proposed by this paper earlier, that the presence of foreign institutional investors, who tend to trade on private information, help to eliminate the turnover premium. Although the evidence is also consistent with the view that the turnover premium may have arisen from overconfidence in individual investors, it is nevertheless premature to jump to such conclusion before any risk adjustment is made to the returns reported in panel $\mathrm{A}$ of Table 4.

However, turnover premium could also conceivably vary with market capitalization, or size, of a stock, as individual investors herd into small-cap issues with limited private information relative to their institutional counterparts. This issue is especially acute in Taiwan, since foreign institutional investors prefer to invest in large-cap issues for better liquidity. Therefore, the absence of turnover premium in the high $\mathrm{FINI} \%$ portfolio may also arise from the fact that foreign institutional investors happen to concentrate in largecap issues with weaker turnover premium to begin with. The descriptive statistics presented in Panel B of Table 4 substantiate this concern. The turnover premium monotonically decreases from small- to large-cap stocks, with monotonically increasing presence of foreign institutional investors. 
Table 4: Summary Statistics: FINI- and Size-Turnover Rate Double Sort Portfolios

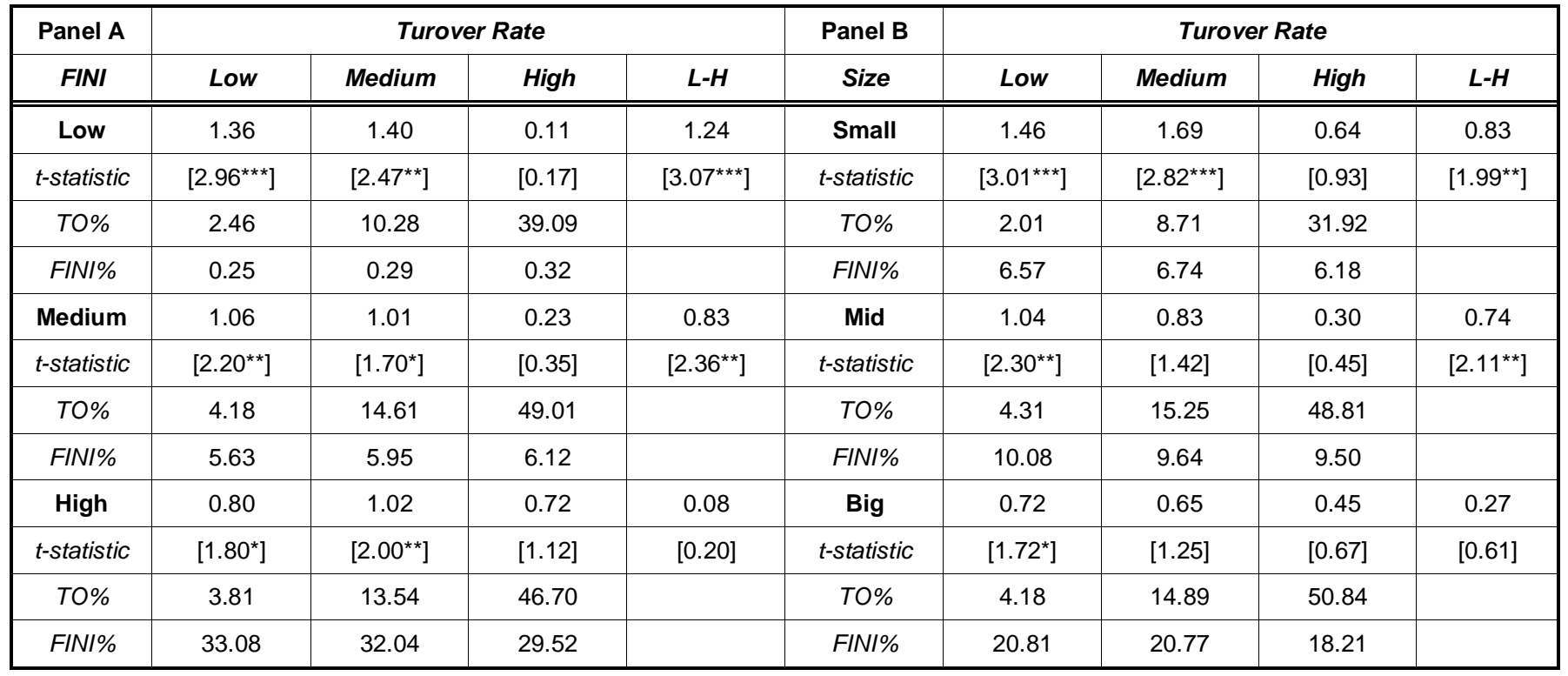

The influence of foreign institutional investors on turnover premium may also be seen, although to a lesser degree, when the turnover rate is double sorted with both $\mathrm{BM}$ ratio and 6-month past return, respectively, as evidenced in Table 5 below.

In panel $A$ of Table $\mathbf{5}$, the turnover premium associated with both high BM and Low BM ratios are all positive and significant at less than $5 \%$ level. However, the magnitude of turnover premium for the low BM portfolio is only about half of that for the high BM portfolio. This pattern is accompanied by higher FINI\% in low BM portfolio than that in its high BM counterpart.
A similar pattern may be observed in panel B of Table $\mathbf{5}$, although the $\mathrm{FINI} \%$ in past winner portfolio is only slightly higher than that in past loser portfolio. One potential explanation is that momentum effect has never been documented conclusively in Taiwan equity market, unlike the positive and significant returns that have been documented in most developed markets and some emerging markets.

\section{B. Turnover Rate Triple-Sort Portfolios}

The evidence in the previous section suggests that the influence of foreign institutional investors on Taiwan

Table 5: Summary Statistics: BM- and Past Return-Turnover Rate Double Sort Portfolios

\begin{tabular}{|c|c|c|c|c|c|c|c|c|c|}
\hline \multirow{2}{*}{$\begin{array}{c}\text { Panel A } \\
\text { BM Ratio }\end{array}$} & \multicolumn{4}{|c|}{ Turover Rate } & \multirow{2}{*}{$\begin{array}{c}\text { Panel B } \\
\begin{array}{c}\text { Past } \\
\text { Return }\end{array}\end{array}$} & \multicolumn{4}{|c|}{ Turover Rate } \\
\hline & Low & Medium & High & Low-High & & Low & Medium & High & $L-H$ \\
\hline High & 2.73 & 2.22 & 1.29 & 1.43 & Loser & 1.36 & 1.10 & -0.01 & 1.37 \\
\hline t-statistic & {$\left[5.09^{* * *}\right]$} & {$\left[3.69^{* * *}\right]$} & {$\left[1.90^{\star}\right]$} & {$\left[3.75^{\star * *}\right]$} & $t$-statistic & {$\left[2.37^{* *}\right]$} & [1.63] & {$[-0.02]$} & {$\left[4.00^{* * *}\right]$} \\
\hline TO\% & 5.06 & 16.54 & 41.94 & & TO\% & 2.97 & 10.86 & 35.89 & \\
\hline FINI\% & 8.07 & 8.98 & 8.03 & & FINI\% & 9.85 & 10.68 & 11.02 & \\
\hline Medium & 1.62 & 1.79 & 1.27 & 0.35 & Medium & 1.06 & 1.11 & 0.21 & 0.85 \\
\hline$t$-statistic & {$\left[3.81^{* \star *}\right]$} & {$\left[3.41^{* \star *}\right]$} & {$\left[2.05^{\star \star}\right]$} & [1.11] & $t$-statistic & {$\left[2.52^{\star \star}\right]$} & {$\left[2.14^{\star \star}\right]$} & {$[0.35]$} & {$\left[2.55^{\star \star}\right]$} \\
\hline TO\% & 5.65 & 19.49 & 54.39 & & TO\% & 3.12 & 11.38 & 39.08 & \\
\hline FINI\% & 11.93 & 12.55 & 11.45 & & FINI\% & 12.05 & 12.39 & 12.05 & \\
\hline Low & 1.62 & 1.42 & 0.84 & 0.78 & Winner & 1.30 & 0.92 & 0.37 & 0.93 \\
\hline$t$-statistic & {$\left[3.48^{* * *}\right]$} & {$\left[2.64^{* * *}\right]$} & [1.33] & {$\left[2.12^{* *}\right]$} & $t$-statistic & {$\left[2.93^{\star * *}\right]$} & {$\left[1.68^{*}\right]$} & {$[0.57]$} & {$\left[2.40^{* *}\right]$} \\
\hline TO\% & 5.59 & 21.95 & 65.52 & & TO\% & 5.34 & 19.84 & 60.64 & \\
\hline FINI\% & 16.81 & 15.85 & 14.40 & & FINI\% & 13.43 & 14.32 & 13.27 & \\
\hline
\end{tabular}


turnover premium may be intertwined with the stylized market anomalies examined therein. In the next section, this issue will be dealt with by a triple-sort procedure that will reveal the extent to which foreign institutional influence turnover premium in Taiwan. In addition, the risk-adjusted returns derived from the models discussed in Section I are reported along with the excess returns, so that the influence from systematic risk on turnover premium may also be examined together with that from foreign institutional investors.

The summary statistics of size-FINI-turnover sorted portfolios are reported in Table 6 . The statistics associated with small-, mid- and large-cap portfolios are reported in panel $A, B$ and $C$ respectively. Each panel contains four tables that report the excess return, CAPM, FF3 and CCAPM risk-adjusted returns of the portfolios, respectively.

Comparing the tables entitled "Excess Return" across three size groups, it is evident that the degree of foreign institutional participation in a stock inversely affects the magnitude and statistical significance of turnover premium, regardless which size group is examined. The turnover premiums for both low- and mid-level FINI\% in the small-cap group are $0.96 \%$ and $1.21 \%$ per month, respectively. In contrast, the turnover premium for high $\mathrm{FINI} \%$ among small-cap stocks is $0.19 \%$ per month that is not significantly different from zero. The same pattern persists, if not stronger, in the mid-cap group. Even in the large-cap group where none of the turnover premiums is significant, those quantities still exhibit a monotonically decreasing pattern from low to high FINI\%. Therefore, it is safe to state that the influence of foreign institutional presence on turnover premium does not arise from its participation in large-cap stocks.

The turnover premiums observed in Table 6 survive the conventional risk adjustment using both unconditional CAPM and Fama-French three-factor model. For example, the CAPM-adjusted turnover premiums for low- and mid-level FINI\% portfolios are $1.08 \%$ and $1.38 \%$ per month, respectively, and both are significant at less than $5 \%$ level. The FF-3-adjsuted turnover premiums for low- and mid-level FINI\% portfolios are highly significant at $1.13 \%$ and $1.41 \%$ per month, respectively. However, the turnover premiums disappear when adjusted by the conditional CAPM. These patterns are observed consistently across all size groups. In fact, the (C)CAPM-adjusted turnover premium for the small-cap group is now negatively significant at $-1.32 \%$ per month. This negative riskadjusted turnover premium is consistent with the findings reported in Chuang and Susmel (2011) that institutional investors tend to herd into stocks based on their private information instead of being driven by emotional and behavioral urges. This phenomenon should be easier to observe in the small-cap universe, where institutional investors possess the greatest informational advantage over their retail counterparts as information regarding small-cap issues is normally scant due to less analyst coverage.

The statistics in Table 6 yield another interesting observation regarding the source of low turnover premium. Looking at the average excess returns for portfolios across different trading intensity, it is evident that none of the excess return associated with highturnover portfolios is economically and statistically significant. However, the excess returns associated with low-turnover portfolios with low foreign institutional participation rates within small- and mid-cap groups are both economically and statistically significant at $1.66 \%$ and $0.87 \%$ per month, respectively. These returns are still significant after risk-adjustment by unconditional CAPM and FF-3 models, but cease to retain their significance when adjusted by the conditional CAPM. The resulting (C)CAPM-adjusted turnover premiums are therefore rendered insignificant.

The evidence presented in Table 6 generally supports the main proposition of this paper, namely, the presence of foreign institutional investors helps to remove the turnover premium that may have in part arisen from overconfidence on the part of individual or retail investors in Taiwan. However, turnover premium disappear after it is risk-adjusted by (C)CAPM. Therefore, one cannot rule out the role of time-varying risk premium in explaining the turnover premium. In order to see if the empirical findings documented in Table 6 are robust to other market anomalies, the same triple sort procedure is applied to BM ratios and 6 -month past returns. The results are summarized in Tables $\mathbf{7}$ and $\mathbf{8}$, respectively.

For stocks with high and low BM ratios, the turnover premiums with low FINI\% are all positive and significant at less than $5 \%$ level. Stocks with medium $\mathrm{BM}$ ratios do not exhibit statistically significant turnover premiums, although their magnitude still monotonically declines with increasing $\mathrm{FINI} \%$. The risk adjustment made by either unconditional CAPM or FF3 model fails to explain, and in most cases even exacerbates, turnover premium. Only the (C)CAPM-adjusted 
Table 6: Summary Statistics: Size-FINI-Turnover-Sorted Portfolios

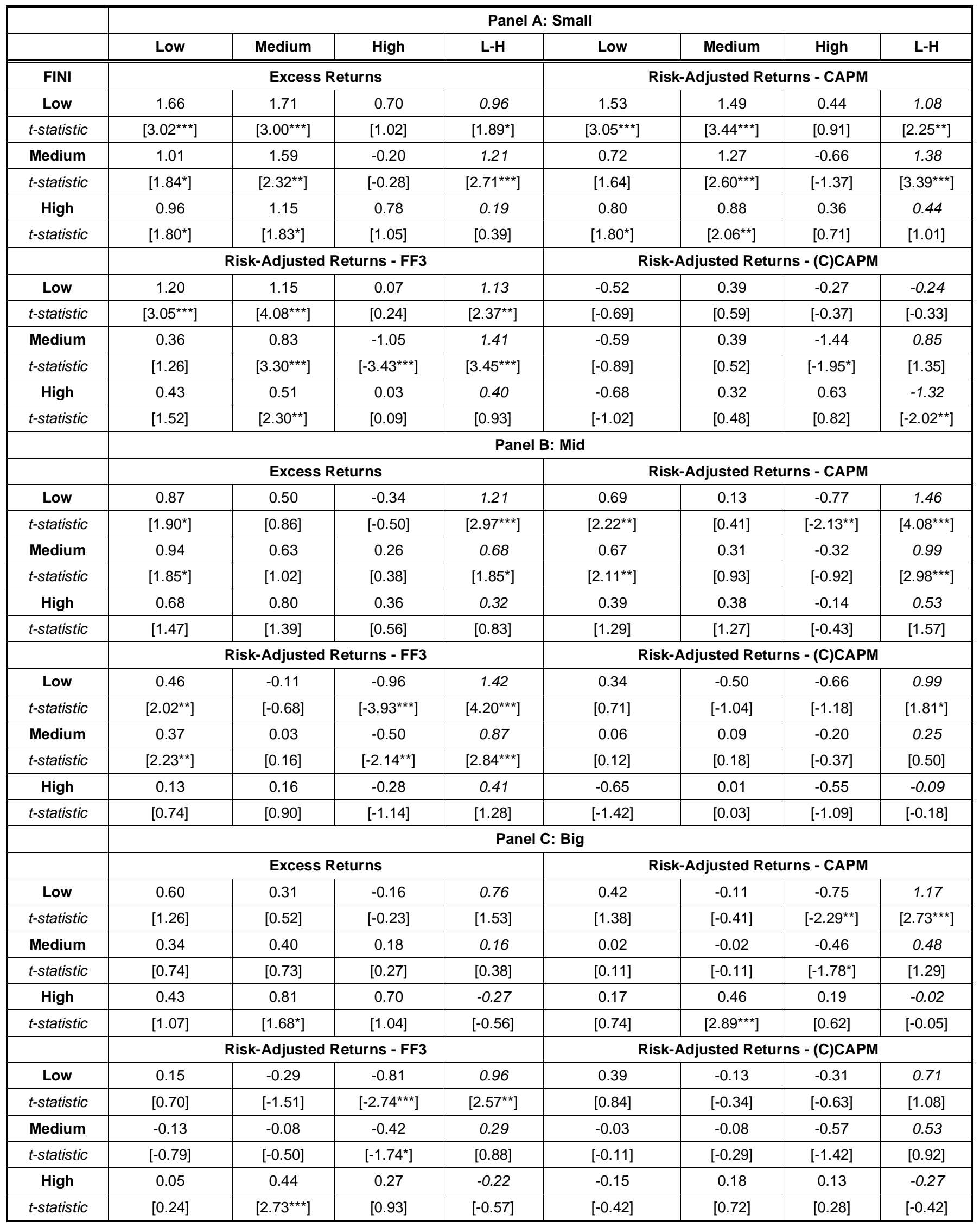


Table 7: Summary Statistics: BM-FINI-Turnover-Sorted Portfolios

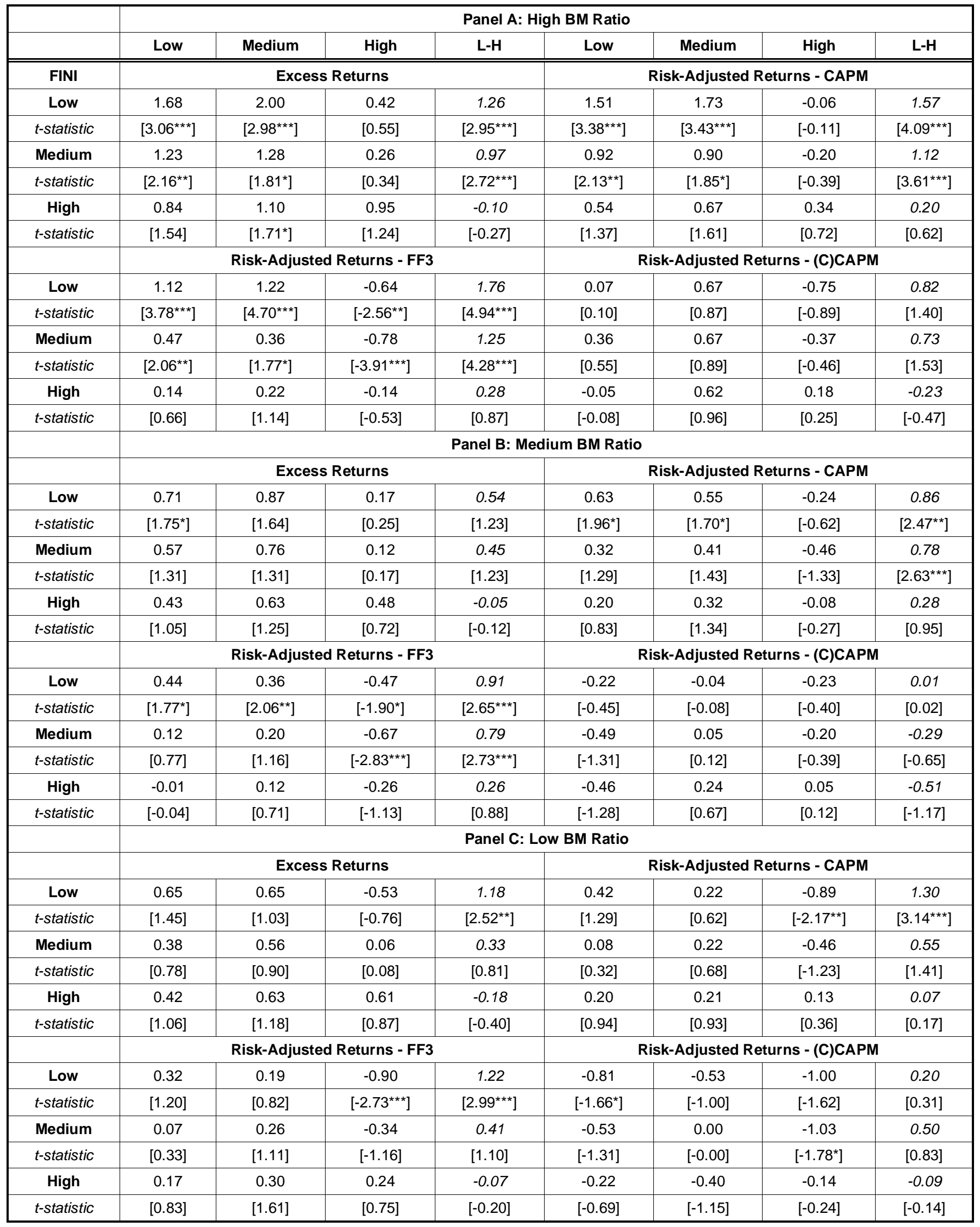


Table 8: Summary Statistics: Past Return-FINI-Turnover-Sorted Portfolios

\begin{tabular}{|c|c|c|c|c|c|c|c|c|}
\hline & \multicolumn{8}{|c|}{ Panel A: Loser } \\
\hline & Low & Medium & High & L-H & Low & Medium & High & L-H \\
\hline FINI & \multicolumn{4}{|c|}{ Excess Returns } & \multicolumn{4}{|c|}{ Risk-Adjusted Returns - CAPM } \\
\hline$t$-statistic & {$\left[2.28^{* *}\right]$} & {$\left[1.75^{\star}\right]$} & {$[-0.87]$} & {$\left[4.39^{* * *}\right]$} & {$\left[2.43^{* *}\right]$} & {$\left[1.75^{\star}\right]$} & {$\left[-2.20^{* *}\right]$} & {$\left[5.21^{* * *}\right]$} \\
\hline Medium & 1.09 & 0.99 & -0.16 & 1.25 & 0.74 & 0.56 & -0.74 & 1.49 \\
\hline High & 0.80 & 0.51 & 0.24 & 0.55 & 0.50 & 0.09 & -0.36 & 0.86 \\
\hline \multirow[t]{2}{*}{ t-statistic } & [1.32] & {$[0.79]$} & {$[0.34]$} & {$[1.37]$} & {$[1.20]$} & {$[0.25]$} & {$[-0.91]$} & {$\left[2.24^{* *}\right]$} \\
\hline & \multicolumn{4}{|c|}{ Risk-Adjusted Returns - FF3 } & \multicolumn{4}{|c|}{ Risk-Adjusted Returns - (C)CAPM } \\
\hline Low & 0.80 & 0.41 & -1.50 & 2.31 & 0.41 & 0.87 & -0.85 & 1.26 \\
\hline$t$-statistic & {$\left[2.29^{* *}\right]$} & [1.41] & {$\left[-4.18^{* * *}\right]$} & {$\left[5.24^{* * *}\right]$} & {$[0.56]$} & [1.19] & {$[-1.11]$} & {$\left[1.89^{*}\right]$} \\
\hline \multirow[t]{3}{*}{ t-statistic } & [0.51] & {$[-0.50]$} & {$[-1.51]$} & {$\left[1.91^{*}\right]$} & [0.65] & {$[1.04]$} & {$[-0.06]$} & {$[0.76]$} \\
\hline & \multicolumn{8}{|c|}{ Panel B: Medium Past Return } \\
\hline & \multicolumn{4}{|c|}{ Excess Returns } & \multicolumn{4}{|c|}{ Risk-Adjusted Returns - CAPM } \\
\hline Low & 0.86 & 1.04 & 0.02 & 0.84 & 0.69 & 0.85 & -0.36 & 1.06 \\
\hline$t$-statistic & {$\left[1.96^{\star}\right]$} & {$\left[1.92^{*}\right]$} & {$[0.03]$} & {$\left[2.28^{* *}\right]$} & {$\left[2.17^{* *}\right]$} & {$\left[2.43^{* *}\right]$} & {$[-1.05]$} & {$\left[3.44^{* * *}\right]$} \\
\hline Medium & 0.87 & 0.78 & -0.11 & 0.98 & 0.69 & 0.40 & -0.66 & 1.35 \\
\hline$t$-statistic & {$\left[1.90^{*}\right]$} & {$[1.41]$} & {$[-0.17]$} & {$\left[2.65^{* * *}\right]$} & {$\left[2.40^{* *}\right]$} & {$[1.44]$} & {$\left[-2.18^{* *}\right]$} & {$\left[4.37^{* * *}\right]$} \\
\hline High & 0.77 & 0.79 & 0.23 & 0.53 & 0.50 & 0.40 & -0.18 & 0.68 \\
\hline$t$-statistic & {$\left[1.79^{*}\right]$} & [1.58] & {$[0.38]$} & {$[1.42]$} & {$\left[1.89^{*}\right]$} & {$\left[1.81^{\star}\right]$} & {$[-0.68]$} & {$\left[2.05^{\star *}\right]$} \\
\hline \multirow[t]{3}{*}{$t$-statistic } & {$[1.46]$} & {$[1.38]$} & {$[-1.12]$} & {$\left[1.74^{*}\right]$} & {$[-0.15]$} & [1.48] & {$[0.55]$} & {$[-0.58]$} \\
\hline & \multicolumn{8}{|c|}{ Panel C: Winner } \\
\hline & \multicolumn{4}{|c|}{ Excess Returns } & \multicolumn{4}{|c|}{ Risk-Adjusted Returns - CAPM } \\
\hline Low & 1.14 & 1.05 & -0.17 & 1.31 & 0.91 & 0.81 & -0.66 & 1.57 \\
\hline$t$-statistic & {$\left[2.27^{\star *}\right]$} & {$\left[1.79^{\star}\right]$} & {$[-0.27]$} & {$\left[2.83^{* * *}\right]$} & {$\left[2.35^{* *}\right]$} & {$\left[2.10^{* *}\right]$} & {$\left[-1.82^{*}\right]$} & {$\left[3.65^{\star * *}\right]$} \\
\hline Medium & 0.90 & 0.46 & 0.27 & 0.63 & 0.66 & 0.15 & -0.31 & 0.97 \\
\hline t-statistic & {$\left[1.79^{\star}\right]$} & {$[0.78]$} & {$[0.39]$} & {$[1.57]$} & {$\left[1.98^{\star *}\right]$} & {$[0.47]$} & {$[-0.88]$} & {$\left[2.67^{\star \star \star}\right]$} \\
\hline High & 1.00 & 0.75 & 0.72 & 0.29 & 0.74 & 0.39 & 0.27 & 0.48 \\
\hline \multirow[t]{2}{*}{$t$-statistic } & {$\left[2.36^{* *}\right]$} & [1.40] & [1.03] & {$[0.64]$} & {$\left[2.80^{* * \star}\right]$} & [1.53] & [0.73] & [1.26] \\
\hline & \multicolumn{4}{|c|}{ Risk-Adjusted Returns - FF3 } & \multicolumn{4}{|c|}{ Risk-Adjusted Returns - (C)CAPM } \\
\hline Low & 0.69 & 0.60 & -0.84 & 1.53 & -0.80 & -0.27 & -1.34 & 0.54 \\
\hline$t$-statistic & {$\left[2.12^{\star \star}\right]$} & {$\left[2.17^{\star *}\right]$} & {$\left[-3.12^{* * *}\right]$} & {$\left[3.61^{* * *}\right]$} & {$[-1.39]$} & {$[-0.45]$} & {$\left[-2.41^{* *}\right]$} & {$[0.83]$} \\
\hline Medium & 0.45 & -0.02 & -0.36 & 0.81 & -0.70 & -0.99 & -1.07 & 0.37 \\
\hline t-statistic & {$\left[1.90^{*}\right]$} & {$[-0.07]$} & {$[-1.24]$} & {$\left[2.37^{\star *}\right]$} & {$[-1.41]$} & {$\left[-2.11^{* *}\right]$} & {$\left[-2.01^{* *}\right]$} & {$[0.67]$} \\
\hline High & 0.61 & 0.33 & 0.26 & 0.35 & -0.25 & -0.62 & -0.33 & 0.08 \\
\hline$t$-statistic & {$\left[2.62^{* * *}\right]$} & [1.46] & {$[0.77]$} & [0.96] & {$[-0.65]$} & {$[-1.65]$} & {$[-0.60]$} & {$[0.13]$} \\
\hline
\end{tabular}


turnover premiums are rendered insignificant across all spectrum of BM ratios.

The potential source of turnover premium, as with the size-FINI\%-turnover rate-sorted case, appears to arise from portfolios with low turnover rates and low-tomedium FINI\% within the high BM ratio group, where the monthly average excess returns were highly significant at $1.68 \%$ and $1.23 \%$ respectively. The average excess return to the portfolio with medium BM ratio, low FINI\% and low turnover rate was also significant, although to a lesser degree, at $0.71 \%$ per month. These premiums are not explained by unconditional CAPM and FF-3 model, but (C)CAPM captures them quite nicely.

Similarly, Table 8 shows that lower FINI\% tends to produce larger and more significantly positive turnover premiums for stocks with low to medium past 6-month cumulative returns, but the turnover premium for high FINI\% stocks are insignificant. Risk adjustments made by unconditional CAPM and FF-3 model do little to explain the patterns observed in these premiums, but the (C)CAPM risk adjustment successfully account for the observed premiums. This is true across all past returns groups. The significant average excess returns from most low-turnover rate portfolios across pastreturns groups point to the potential source of turnover premiums. Within the loser group, the excess returns associated with the low turnover rate, low-to-medium FINI\% portfolios are $1.36 \%$ and $1.09 \%$ per month each. Within the medium past-return group, the monthly excess returns range from $0.77 \%$ to $0.87 \%$, which are all significant regardless of $\mathrm{FINI} \%$. Within the winner group, the average monthly excess returns range from $0.90 \%$ to $1.14 \%$, which are all statistically significant. These returns disappear when time-varying risk premium is accounted for, as with the cases for other triple-sort portfolios.

Again, even though the (C)-adjusted turnover premiums are now insignificant, but their magnitude still changes inversely with the degree of $\mathrm{FINI} \%$. For example, the turnover premiums for the winner group range from $1.31 \%$ to $0.29 \%$ per month as $\mathrm{FINI} \%$ increases from low to high level. The (C)CAPMadjusted turnover premiums for the same group range from $0.54 \%$ to $0.08 \%$ per month as $\mathrm{FINI} \%$ increases. Whether turnover premiums are risk adjusted or not, the increasing presence of foreign institutional investors almost always significantly reduces the magnitude of turnover premiums. These findings provide evidence supporting the view that turnover premium arises in large part from overconfident retail investors. Foreign institutional investors, who tend to trade on private information, to some extent attenuate the premium.

In a nutshell, the findings in Tables 7 and 8 basically reflect similar observation to that in Table 6 that have been discussed in depth in previous passages. To reiterate, the level of foreign institutional investors strongly affect the magnitude and significance of turnover premium, causing them to decrease monotonically from low- to high-level FINI\% portfolios. The (C)CAPM risk-adjustment captures the low turnover premium completely in our data, but the increasing presence of foreign institutional still cause the magnitude of turnover premium to decrease monotonically. These patterns are observed regardless which stylized market anomaly is used in the triple-sort procedure, be it size, BM ratios, or 6-month past returns.

\section{CONCLUSION}

The extent research has found that stocks with lower turnover rate tend to outperform their highturnover counterparts by a wide and statistically significant margin. The persistence of this phenomenon, even after conventional risk adjustment such as unconditional CAPM and Fama-French three factor model, makes most researchers lean toward behavioral explanations. Odean (1998) theorized that the overconfident traders tend to drive up expected trading volume. Some empirical findings documented that individual, or retail, investors tend to be overconfident after experiencing recent gains, which in turn leads to below market returns subsequently. Other empirical evidence suggested that institutional investors tend to herd on private information, while herding in individual investors tends to be driven by overconfidence. Therefore, this paper sets out to test the possibility that turnover premium may vary inversely with the degree of foreign institutional investing in Taiwan stocks. The possibility of timevarying risk premium is accounted for, in the form of (C)CAPM framework proposed by Lettau and Ludvigson (2001) and Kang et al. (2011), to see if the persistence of low turnover premium is due to inappropriate risk adjustment.

The current study reports the following findings. First, the low turnover premium is strong and positive in Taiwan equity market. Since Taiwan equity market has been a peculiar market place where the evidence 
concerning many of the stylized effects, for example, size, book-to-market ratio, and momentum, is dubious at best, a significant turnover premium makes it arguably one of the few, if not the only one, phenomena that is consistent with other developed markets by far. Second, the notion that the degree of foreign institutional participation in a stock varies inversely is supported by the data. In general, low turnover premium is confined to those stocks with little interest from foreign institutional investors. Further, the source of turnover premium appears to arise from low turnover stocks that exhibit positive and significant average excess returns. In contrast, the average excess returns for high turnover stocks are often indistinguishable from zero. This distinction persists even when turnover rate is paired with FINI\%, market capitalization, BM ratios and 6-month past returns.

The low turnover premium does not disappear with risk adjustment such as unconditional CAPM and Fama-French three factor model, which is consistent with what previous studies focusing on U.S. market had found. However, when the (C)CAPM is employed for risk adjustment, the low turnover premium vanishes. Consistent with the previous passage, the disappearance of turnover premium stems from the low turnover portfolios, which saw their positive excess returns drop significantly once the possibility of timevarying risk premium is accounted for. Nevertheless, the magnitude of (C)CAPM-adjusted turnover premium still monotonically decreases with increasing foreign institutional interest. Therefore, this paper concludes that insufficient risk adjustment may be an important factor in explaining turnover premium, but the influence of investor overconfidence cannot be completely ruled out, at least for the data studied herein.

The main findings that the investment decisions of local investors were substantially influenced by overconfidence, and that the presence of foreign institutional investors partially remedied the consequences induced by investor overconfidence, have important implication for Taiwan's policy toward foreign institutional investors. Taiwan equity market have traditionally been heavily populated by retail investors, a group of investors who were typically illequipped to make informed investing decisions due to the lack of resources relative to their foreign institutional counterpart. The resulting security prices might not necessarily reflect the fair value of public companies, which in turn could potentially distort allocation of scarce resources for economic development. The increasing presence of foreign investors in Taiwan should therefore help restore the distortion to some extent.

\section{REFERENCES}

Barber, Brad M., Yi-Tsung Lee, Yu-Jane Liu, and Terrance Odean. 2009. "Just How Much Do Individual Investors Lose by Trading?" Review of Financial Studies 22(2):609-632. http://dx.doi.org/10.1093/rfs/hhn046

Barber, Brad M., and Terrance Odean. 2000. "Trading Is Hazardous to Your Wealth: The Common Stock Investment Performance of Individual Investors." Journal of Finance 55(2):773-806. http://dx.doi.org/10.1111/0022-1082.00226

Barber, Brad M., and Terrance Odean. 2008. "All That Glitters: The Effect of Attention and News on the Buying Behavior of Individual and Institutional Investors." Review of Financial Studies 21(2):785-818. http://dx.doi.org/10.1093/rfs/hhm079

Chordia, Tarun, Richard Roll, and Avanidhar Subrahmanyam. 2011. "Recent Trends in Trading Activity and Market Quality." Journal of Financial Economics 101(2):243-263. http://dx.doi.org/10.1016/j.jfineco.2011.03.008

Chou, Pin-Huang, Tsung-Yu Huang, and Hung-Jeh Yang. 2013. "Arbitrage Risk and the Turnover Anomaly." Journal of Banking and Finance 37(11):4172-4182. http://dx.doi.org/10.1016/j.jbankfin.2013.07.011

Chuang, Wen-I, and Rauli Susmel. 2011. "Who Is the More Overconfident Trader? Individual vs. Institutional Investors." Journal of Banking and Finance 35(7):1626-1644. http://dx.doi.org/10.1016/j.jbankfin.2010.11.013

Datar, Vinay T., Narayan Y. Naik, and Robert Radcliffe. 1998. "Liquidity and Stock Returns: An Alternative Test." Journal of Financial Markets 1(2):203-219. http://dx.doi.org/10.1016/S1386-4181(97)00004-9

Ferson, Wayne E. 1989. "Changes in Expected Security Returns, Risk, and the Level of Interest Rates." The Journal of Finance 44(5):1191-1217. http://dx.doi.org/10.1111/j.1540-6261.1989.tb02650.x

Ferson, Wayne E., and Campbell R. Harvey. 1991. "The Variation of Economic Risk Premiums." Journal of Political Economy 99(2):385-415. http://dx.doi.org/10.1086/261755

Ferson, Wayne E., and Campbell R. Harvey. 1999. "Conditioning Variables and the Cross Section of Stock Returns." The Journal of Finance 54(4):1325-1360.

http://dx.doi.org/10.1111/0022-1082.00148

Gervais, Simon, and Terrance Odean. 2001. "Learning to $\mathrm{Be}$ Overconfident." Review of Financial Studies 14(1):1-27. http://dx.doi.org/10.1093/rfs/14.1.1

He, Wen, and Jiangfeng Shen. 2014. "Do Foreign Investors Improve Informational Efficiency of Stock Prices? Evidence from Japan." Pacific-Basin Finance Journal 27(C):32-48. http://dx.doi.org/10.1016/i.pacfin.2014.01.005

Hsieh, Shu-Fan. 2013. "Individual and Institutional Herding and the Impact on Stock Returns: Evidence from Taiwan Stock Market." International Review of Financial Analysis 29(C):175-188.

http://dx.doi.org/10.1016/j.irfa.2013.01.003

Kang, Jangkoo, Tong Suk Kim, Changjun Lee, and Byoung-Kyu Min. 2011. "Macroeconomic Risk and the Cross Section of Stock Returns." Journal of Banking and Finance 35(12):3158-3173. http://dx.doi.org/10.1016/j.jbankfin.2011.04.012

Lee, M.C. Charles, and Bhaskaran Swaminathan. 2000. "Price Momentum and Trading Volume." Journal of Finance 55(5):2017-2069.

http://dx.doi.org/10.1111/0022-1082.00280 
Lettau, Martin, and Sydney Ludvigson. 2001. "Resurrecting the (C)CAPM:A Cross-Sectional Test When Risk Premium Are Time-Varying." Journal of Political Economy 109(6):12381287.

http://dx.doi.org/10.1086/323282

Odean, Terrance. 1998. "Volume, Volatility, Price, and Profit When All Traders Are Above Average." Journal of Finance 53(6):1887-1934. http://dx.doi.org/10.1111/0022-1082.00078

Odean, Terrance. 1999. "Do Investors Trade Too Much?" American Economic Review 89(5):1279-98. http://dx.doi.org/10.1257/aer.89.5.1279

Schuppli, Michael, and Martin T. Bohl. 2010. "Do foreign Institutional Investors Destablize China's A-share Markets?" Journal of International Financial Markets, Institutions and Money 20(1):36-50. http://dx.doi.org/10.1016/j.intfin.2009.10.004

Shiu, Yih-Wen, Chun I. Lee and Kimberly C. Gleason. 2014. "Institutional Shareholdings and the January Effects in Taiwan." Journal of Multinational Financial Management 27(C):49-66.

http://dx.doi.org/10.1016/j.mulfin.2014.05.005

Statman, Meir, Steven Thorley and Keith Vorkink. 2006. "Investor Overconfidence and Trading Volume." Review of Financial Studies 19(4):1531-1565. http://dx.doi.org/10.1093/rfs/hhj032
Yang, Jack J.W. 2002. "The Information Spillover between Stock Returns and Institutional Investors' Trading Behavior in Taiwan." International Review of Financial Analysis 11(4):533-547.

http://dx.doi.org/10.1016/S1057-5219(02)00069-8

Yates, J. Frank, Ju-Whei Lee, and Hiromi Shinotsuka. 1996. "Beliefs About Overconfidence, Including Its Cross-national Variation." Organizational Behavior and Human Decision Processes 65(2):138-147. http://dx.doi.org/10.1006/obhd.1996.0012

Yates, J. Frank, Ju-Whei Lee, and Julie GG. Bush. 1997. "General Knowledge Overconfidence: Cross-national Variations, Response Style, and "Reality"." Organizational Behavior and Human Decision Processes 70(2):87-94. http://dx.doi.org/10.1006/obhd.1997.2696

Yates, J. Frank, Ju-Whei Lee, Hiromi Shinotsuka, Andrea L Patalano, and Winston R Sieck. 1998. "Cross-Cultural Variations in Probability Judgment Accuracy: Beyond General Knowledge Overconfidence?" Organizational Behavior and Human Decision Processes 74(2):89-117. http://dx.doi.org/10.1006/obhd.1998.2771

(C) 2015 Chen and Lee; Licensee Lifescience Global.

This is an open access article licensed under the terms of the Creative Commons Attribution Non-Commercial License (http://creativecommons.org/licenses/by-nc/3.0/) which permits unrestricted, non-commercial use, distribution and reproduction in any medium, provided the work is properly cited. 